\title{
Pro-survival and anti-apoptotic properties of androgen receptor signaling by oxidative stress promote treatment resistance in prostate cancer
}

\author{
Masaki Shiota, Akira Yokomizo and Seiji Naito \\ Department of Urology, Graduate School of Medical Sciences, Kyushu University, 3-1-1 Maidashi, Higashi-ku, Fukuoka 812-8582, \\ Japan \\ (Correspondence should be addressed to M Shiota; Email: shiota@uro.med.kyushu-u.ac.jp)
}

\begin{abstract}
Oxidative stress caused by an increase in reactive oxygen species levels or a decrease in cellular antioxidant capacity can evoke the modulation of various cellular events including androgen receptor (AR) signaling via direct or indirect interactions. In this review, we summarize the mechanisms of $A R$ activation by oxidative stress including: i) AR overexpression; ii) AR activation by AR co-regulators or intracellular signal transduction pathways; iii) generation of AR mutations or splice variants; and iv) de novo androgen synthesis. AR signaling augmented by oxidative stress appears to contribute to pro-survival and anti-apoptotic effects in prostate cancer cells in response to androgen deprivation therapy. In addition, AR signaling suppresses anti-survival and pro-apoptotic effects in prostate cancer cells in response to various cytotoxic and tumorsuppressive interventions including taxanes and radiation through the modulation of $\beta$ III-tubulin and ataxia telangiectasia-mutated kinase expression respectively. Taken together, AR signaling appears to render prostate cancer cells refractory to various therapeutic interventions including castration, taxanes, and radiation, indicating that $A R$ signaling is a comprehensive resistant factor and crucial target for prostate cancer treatment.
\end{abstract}

Endocrine-Related Cancer (2012) 19 R243-R253

\section{Introduction}

Prostate cancer is the most common non-cutaneous cancer and the second leading cause of male cancerrelated mortality in western countries. A special characteristic of prostate tumors is their dependence on androgen receptor (AR) signaling for their carcinogenesis, development, and progression (Basu \& Tindall 2010). Inversely, androgen deprivation therapy, which reduces androgen production, or antiandrogen agents, which interfere with AR function, are gold-standard treatments for recurrent or advanced prostate cancer (Miyamoto et al. 2004). However, androgen-dependent prostate cancer eventually develops into castration-resistant prostate cancer (CRPC), which can be attributable to augmented prosurvival and anti-apoptotic properties by AR signaling and others (Niraula et al. 2012). Against CRPC, few therapeutics including taxane chemotherapy are not curative, only ameliorating cancer-caused symptoms and prolonging survival for a few months. Recently, novel AR-targeting agents such as the cytochrome P17 inhibitor abiraterone acetate and the second-generation anti-androgen MDV3100 have been proved to reduce tumor burden and improve overall survival in CRPC patients, although their efficiencies are also limited, prolonging survival for only 3-5 months (de Bono et al. 2011, Scher et al. 2012).

Reactive oxygen species (ROS) include superoxide $\left(\mathrm{O}_{2}^{-}\right)$, hydrogen peroxide $\left(\mathrm{H}_{2} \mathrm{O}_{2}\right)$, and hydroxyl radicals $(\mathrm{HO} \cdot)$, and are produced by the partial reduction of oxygen. Cellular ROS are generated endogenously, mainly during the process of mitochondrial oxidative phosphorylation, or can arise exogenously from xenobiotic compounds. Oxidative stress is caused when the cellular antioxidant defense system is overwhelmed by an increase in ROS levels or 
a decrease in cellular antioxidant capacity. This stress leads to the damage of nucleic acids, proteins, and lipids, and has been implicated in various disorders including carcinogenesis (Trachootham et al. 2009), neurodegenerative diseases (Andersen 2004), atherosclerosis, diabetes (Paravicini \& Touyz 2006), and aging (Haigis \& Yankner 2010). Oxidative stress also has effects on the redox regulation of redox-reactive cysteine (Cys) residues in redox-sensitive proteins. Oxidation of these residues forms reactive sulfenic acid (-SOH) that can form disulfide bonds with nearby cysteine residues $(-\mathrm{S}-\mathrm{S}-$ ) or undergo further oxidation to sulfinic $\left(-\mathrm{SO}_{2} \mathrm{H}\right)$ or sulfonic $\left(-\mathrm{SO}_{3} \mathrm{H}\right)$ acid. These oxidative modifications change protein structure and thus affect their function. Except where $-\mathrm{SO}_{3} \mathrm{H}$ is involved, these redox modifications can be reversed by reducing systems such as thioredoxin and peroxiredoxin (Roos \& Messens 2011). Thus, oxidative stress can modulate various cellular actions, including AR signaling, via direct or indirect interactions (Ray et al. 2012).

Oxidative stress has been shown to play an important role in the tumorigenesis and progression of prostate cancer (Bostwick et al. 2000, Sharifi et al. 2008, Khandrika et al. 2009), as well as in the conversion of androgen-dependent prostate cancer into CRPC (Sharifi et al. 2008, Shiota et al. 2010, 2011a). Together, these results suggest an intimate cross-talk between oxidative stress and AR signaling. In this review, we summarize the effects of oxidative stress, which plays pro-survival and anti-apoptotic roles against various prostate cancer treatments, on AR signaling.

\section{Oxidative stress by treatment in prostate cancer}

Several experiments in both in vitro and in vivo have indicated that castration induced oxidative stress through redox imbalance by up-regulating ROS production via NADPH oxidases and down-regulating ROS-detoxifying enzymes such as manganese superoxide dismutase (SOD2; Pang et al. 2002, Tam et al. 2003, Best et al. 2005, Shan et al. 2010). Although there are several conflicting studies showing that androgens induce oxidative stress (Pinthus et al. 2007, Pathak et al. 2008), they may reflect a physiological or non-physiological condition. Ripple et al. (1997) reported that the physiological level of androgens decreased oxidative stress while the overloading of androgens induced oxidative stress, suggesting non-specific stress under non-physiological condition. In humans, it was found that androgen deprivation therapy decreases SOD2 expression in biopsy tissues of prostate cancer (Best et al. 2005), and increases oxidative stress in prostate cancer cells as well as in surgically resected tissue of prostate cancer tissues (Shiota et al. 2010, 2012). In addition to androgen deprivation, several treatments against prostate cancer including taxane chemotherapy and radiotherapy are known to induce oxidative stress (Acharya et al. 2010). Thus, various treatments induce oxidative stress in prostate cancer cells, leading to cellular damages as well as modulations of cellular signaling including AR signaling.

\section{Effects of oxidative stress on AR signaling}

In 2008, oxidative stress was reported to be implicated in AR signaling in prostate cancer (Sharifi et al. 2008). SOD2, which regulates ROS levels by converting superoxide to a less reactive species, is reduced by androgen deprivation (Pang et al. 2002, Best et al. 2005) and is down-regulated in CRPC (Best et al. 2005, Quirós et al. 2009). Sharifi et al. (2008) showed that the suppression of SOD2 induced the activation of AR signaling by ROS production via the following pathways. First, several genes involved in steroid metabolism, including $A K R 1 C 3$, were induced by $S O D 2$ knockdown, and this effect was reversed by the treatment with the antioxidant $\mathrm{N}$-acetyl-cysteine (NAC). Changes in the expression of genes related to steroid metabolism can lead to an increase in local de novo androgen synthesis in CRPC, thus contributing to castration resistance via AR reactivation (Titus et al. 2005). Second, five nuclear receptor co-regulators, including NCOA4 (ARA70), were induced by repressing SOD2 in a ROS-dependent manner. AR reactivation can be induced by altering the balance of such steroid receptor co-regulators (Heemers \& Tindall 2007). Lastly, the receptor for interleukin-6 (IL6R) was induced by SOD2 down-regulation, and this effect was reversed by NAC. IL6 activates AR in a STAT3dependent manner, while antibodies to IL6 reverse castration resistance (Lee et al. 2003, Wallner et al. 2006). Furthermore, levels of IL6R are predictive of biochemical recurrence of prostate cancer and metastasis (Shariat et al. 2001, Kattan et al. 2003). Thus, SOD2 repression is found to contribute to castration resistance via AR reactivation by several mechanisms. Inversely, it has been reported that SOD mimetics reduce oxidative stress and exert a suppressive effect on $\mathrm{AR}$ expression, including the expression of $\mathrm{AR}$ splice variants, and have a therapeutic effect on prostate cancer cells (Thomas \& Sharifi 2012). These results suggest that antioxidant therapy is feasible and 
promising for the treatment of prostate cancer, including CRPC. We have also independently found that oxidative stress plays a crucial role in $\mathrm{AR}$ signaling, leading to the development of CRPC (Shiota et al. 2010, 2011a).

Since the findings of Sharifi et al. (2008), further evidence supporting a role of oxidative stress in AR signaling has been acquired. AR signaling in CRPC is aberrantly augmented by the low androgen milieu, via various mechanisms including: i) AR overexpression; ii) AR activation by AR co-regulators or intracellular signal transduction pathways; iii) AR mutations or splice variants; and iv) de novo androgen synthesis. The effects of oxidative stress on AR signaling are reviewed in the following sections.

\section{AR overexpression}

AR overexpression is thought to be one of the major causes of CRPC (Shiota et al. 2011b). Many studies have shown that the progression of CRPC is associated with increased AR expression (Gregory et al. 1998, Zegarra-Moro et al. 2002, Chen et al. 2004, Scher \& Sawyers 2005), which can be attributed to gene amplification, transcriptional up-regulation, translational up-regulation, and decreased degradation. As we summarized previously (Shiota et al. 2011b), various transcription factors activated by oxidative stress, including Twist1 (Shiota et al. 2010), YB-1 (Shiota et al. 2011c), NF-кB (Zhang et al. 2009), Sp1 (Faber et al. 1993, Yuan et al. 2005), Myc (Grad et al. 1999, Lee et al. 2009), CREB (Mizokami et al. 1994), and Foxo3a (Yang et al. 2005), regulate AR expression. In addition, it has recently been shown that the SREBP-1 transcription factor regulates AR expression (Huang et al. 2010), is overexpressed during progression to castration resistance (Ettinger et al. 2004), regulates lipogenesis, and induces oxidative stress via NADPH oxidase 5 (Nox5) expression that can be reversed by the Nox inhibitor diphenyliodonium (DPI). Intriguingly, AR expression was shown to be repressed by DPI, indicating that AR expression by SREBP-1 may be mediated by the Nox pathway (Huang et al. 2012). Lipogenesis by SREBP-1 may also be involved in AR expression, as our findings demonstrated that statin suppresses AR expression by promoting the degradation of the $\mathrm{AR}$ protein (Yokomizo et al. 2011).

As described above, several transcription factors regulate AR expression. In addition, the abovementioned transcription factors may involve the Twist1/YB-1 signaling pathway. NF- $\kappa \mathrm{B}$ (Pham et al. 2007) and Sp1 (Ohkuma et al. 2007) have been shown to promote Twist1 transactivation. Myc (Uramoto et al. 2002) and Twist1 (Shiota et al. 2008a,b, 2009) have been shown to up-regulate YB-1 expression, and YB-1 to increase Twist1 expression via a translational mechanism (Evdokimova et al. 2009), suggesting a mutual regulation between Twist1 and YB-1. Taken together, these results indicate that the abovementioned transcription factors regulate AR expression by mutual interactions, suggesting that Twist 1 and YB-1 may be nodal transcription factors in $A R$ expression (Fig. 1).

In addition to transcription factors, other molecules have been reported to be involved in regulating AR expression, likely through intracellular signaling pathways and transcription factors. BLT2 is a receptor for leukotriene B4 and 12-HETE, and plays a critical role in tumor progression, as indicated by the finding that BLT2 is overexpressed in various cancers (Yoo et al. 2004, Hennig et al. 2008, Choi et al. 2010). Recently, it has been reported that a BLT2-linked pathway evokes ROS production and up-regulates AR expression via the Nox4 pathway, while the Nox inhibitor, DPI, reduces AR expression (Lee et al. 2012). Furthermore, DPI was shown to reduce cell proliferation in prostate cancer cells, including LNCaP cells which express the mutated AR protein and are dependent on AR for growth, but respond to other steroids than androgens and can be driven to a castration-resistant phenotype. In addition to oxidative stress induced by $\mathrm{H}_{2} \mathrm{O}_{2}$, cadmium and zinc chloride, which are known to induce oxidative stress, were

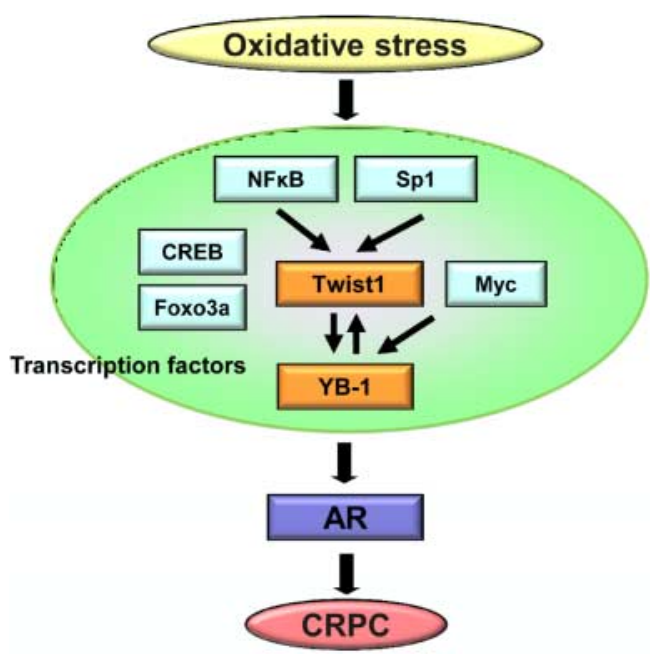

Figure 1 Schematic representation of the links between the transcription factors that induce AR expression and promote the development of CRPC. Full colour version of this figure available via http://dx.doi.org/10.1530/ERC-12-0232. 
reported to increase $\mathrm{AR}$ expression in dysplastic glands of rat prostate (Arriazu et al. 2005). The synthetic antimicrobial chemical mequindox was found to induce oxidative stress and AR overexpression in rat testes, indicating a positive connection between oxidative stress and AR expression (Ihsan et al. 2011). These data suggest that oxidative stress induced by internal and external stimuli induces AR overexpression via various cellular processes.

Contrasting reports suggested that inducers of oxidative stress suppress AR expression. The inducer of oxidative stress, $t$-butyl hydroperoxide, suppresses AR expression in H4IIE rat hepatoma cells, indicating that the effect of oxidative stress on AR expression may differ among cell types, and/or may be derived from differences in concentration and/or pharmacological action among oxidants. Additionally, a curcumin analog shown to induce oxidative stress was reported to partially down-regulate AR expression at the transcriptional level, but not by proteasomal degradation (Fajardo et al. 2012). The effect of the curcumin analog was attenuated by the antioxidant NAC, suggesting that AR down-regulation resulted from oxidative stress mediated by the curcumin analog. However, the oxidative stress-inducing effect of the curcumin analog did not appear to be significant. Furthermore, NAC alone down-regulated $A R$ transcript expression, although NAC reduces oxidative stress, which is inconsistent with the authors' proposal that oxidative stress down-regulates AR expression. Similarly, thymoquinone was shown to induce ROS production and down-regulate AR expression (Koka et al. 2010). However, its effect on AR downregulation was not reversed by NAC, suggesting that either AR down-regulation by thymoquinone induced oxidative stress, or that the effect of thymoquinone on AR expression was independent from its ability to induce oxidative stress.

\section{AR activation by AR co-regulators and intracellular signal transduction pathways}

AR co-regulators modulate the transactivation of AR through interactions with AR (Shiota et al. 2011d). Several AR co-regulators, including peroxiredoxin, Hsp27, and EGR-1, have been reported to be activated by oxidative stress, and thus contribute to AR transactivation (Shiota et al. 2011a). In particular, oxidative stress modulates the redoxsensitive molecule peroxiredoxin via its Cys residues. We previously showed that Cys residues in peroxiredoxin are critical in its function as an $\mathrm{AR}$ co-regulator (Shiota et al. 2011e), suggesting that protein modification of AR co-regulators by ROS affects AR signaling.

Several molecules and intracellular signaling pathways play a role in AR transactivation. As previously summarized, cytokines such as insulinlike growth factor, fibroblast growth factor, epidermal growth factor, and IL6 and signal transduction pathways such as mitogen-activated protein kinase, JAK/STAT, protein kinase A, phosphatidylinositol3-kinase/Akt, and protein kinase $\mathrm{C}$, which may be activated by oxidative stress, can augment $\mathrm{AR}$ function (Shiota et al. 2011a). Thus, oxidative stress can activate AR signaling through intracellular signaling pathways that interact with various transcription factors and co-regulators of transcription factors.

\section{AR mutations and splice variants}

Although oxidative stress is known to evoke DNA mutations, the implications of oxidative stress-induced mutations of the $A R$ gene are unknown (Khandrika et al. 2009). Mutations in the $A R$ gene may change its ligand binding characteristics or its transcriptional activity, resulting in the modulation of its target gene expression (Brooke et al. 2008, Brooke \& Bevan 2009). In addition to $A R$ mutations, several AR splice variants that exhibit transcriptional activity even in the absence of androgen and contribute to the promotion of CRPC have recently been identified (Dehm et al. 2008, Guo et al. 2009, Hu et al. 2009, Sun et al. 2010, Watson et al. 2010). Although a relationship between AR splice variants and oxidative stress has not been reported to date, it is possible that oxidative stress may be implicated in the expression of AR splice variants as it is for splice variants of other genes (Xu \& Chu 2007, Soliman et al. 2009, Takeo et al. 2009). Therefore, future studies should examine the effects of oxidative stress-induced mutations of the $A R$ gene or the expression of AR splice variants.

\section{De novo androgen synthesis}

De novo synthesis of androgen in adrenal glands and tumors has recently been recognized as a potential cause of CRPC (Stanbrough et al. 2006, Locke et al. 2008, Montgomery et al. 2008), the hypothesis of which was proved by the result of the cytochrome P17 inhibitor abiraterone acetate in a clinical trial (de Bono et al. 2011). Although there is no evidence, at present, that oxidative stress promotes androgen synthesis in prostate cancer, several studies have indicated a relationship between oxidative stress and steroidogenesis. For instance, $\mathrm{H}_{2} \mathrm{O}_{2}$ has recently been shown to biphasically regulate androgen synthesis in rat Leydig 
cells, indicating that oxidative stress within physiological levels promotes steroidogenesis (Zhao et al. 2012). These data suggest the possibility that oxidative stress promotes de novo androgen synthesis in prostate cancer cells.

\section{Oxidative stress and resistance to androgen deprivation}

There is a close relationship between oxidative stress and castration resistance in prostate cancer. Oxidative stress activates AR signaling, which promotes a conversion from androgen-dependent to CRPC through pro-survival and anti-apoptotic roles. We found that $\mathrm{H}_{2} \mathrm{O}_{2}$-resistant $\mathrm{LNCaP}$ cell derivatives of androgen-dependent prostate cancer cells have a high level of AR protein expression and exhibit a castrationresistant phenotype (Shiota et al. 2010). In addition, evidence has shown that oxidative stress is increased in CRPC cells, as indicated by higher intracellular ROS levels in castration-resistant $\mathrm{LNCaP}$ derivatives, $\mathrm{C} 4-2$ cells, compared with LNCaP cells (Shigemura et al. 2007), and greater antioxidant protein levels (Kuruma et al. 2005, Shiota et al. 2011e) and the ability to scavenge ROS (Wu et al. 2007) in castration-resistant LNCaP cells and tumors. Thus, AR activation by oxidative stress is thought to render prostate cancer cells resistant to castration.

\section{Pro-survival and anti-apoptotic roles of AR signaling in prostate cancer cells in response to therapeutic interventions other than androgen deprivation}

Similarly to castration resistance by the activation of AR signaling, AR signaling may contribute to the survival and anti-apoptotic effects of other insults on cancer cells. Recently, it has been shown that the heart of $A R$ knockout mice is sensitive to oxidative stress induced by doxorubicin (Ikeda et al. 2010). Similarly, we have shown that $A R$ knockdown sensitizes bladder cancer cells to doxorubicin (Shiota et al. 2012). In addition, AR signaling may be involved in cellular resistance to taxanes including paclitaxel, docetaxel, and cabazitaxel which are key cytotoxic anticancer drugs for prostate cancer, as androgen regulates the expression of the taxane resistance-promoting factor BIII-tubulin (Butler et al. 2001, Mariani et al. 2012). In fact, CRPC cells in which AR was overexpressed developed cross-resistance to taxanes (Kosaka et al. 2011). Furthermore, concurrent therapy with paclitaxel and castration was found to improve the suppression of tumor growth and overall survival compared with sequential therapy with paclitaxel and castration using Shionogi and LNCaP tumor models (Eigl et al. 2005). Similarly to these in vitro studies, administration of docetaxel plus estramustine in addition to androgen deprivation in a clinical setting was shown to improve a prostate-specific antigen response after 3 months (Fizazi et al. 2012). Long-term results and the effects of this treatment regime on overall survival have not yet been obtained. Taken together, these results suggest a favorable outcome from taxane and androgen deprivation combination therapy, and pro-survival and anti-apoptotic roles of AR signaling in response to treatment with taxanes. In addition, androgen and AR expression rendered prostate cancer cells resistant to TGF- $\beta$-induced apoptosis (Zhu et al. 2008). Similarly, administration of androgen inhibited apoptosis induced by the Akt inhibitor LY294002, while the antiandrogen drug flutamide abolished the anti-apoptotic effect of androgen (Kumar et al. 2011). Like cytotoxic agents, radiation cytotoxicity is known to be augmented by the suppression of AR signaling. Numerous lines of evidence have demonstrated that androgen deprivation augments the therapeutic effect of radiation (Granfors et al. 1997, Zietman et al. 1997, Kaminski et al. 2003, Nishiyama 2012). In addition, clinical studies have also shown the favorable effects of castration in combination with radiation on locally advanced prostate cancer with intermediate and high risk (D'Amico et al. 2004, 2008, Denham et al. 2005, 2011, Jones et al. 2011). Interestingly, it has recently been reported that the cell-cycle and DNA repair regulator ataxia telangiectasia-mutated kinase (ATM) contributes to radiation resistance through the up-regulation of AR phosphorylation and activation, which explains the molecular mechanism mediating radiation resistance by AR signaling (Mahajan et al. 2012). In fact, where AR signaling was aberrantly activated in CRPC, cells were found to be cross-resistant to

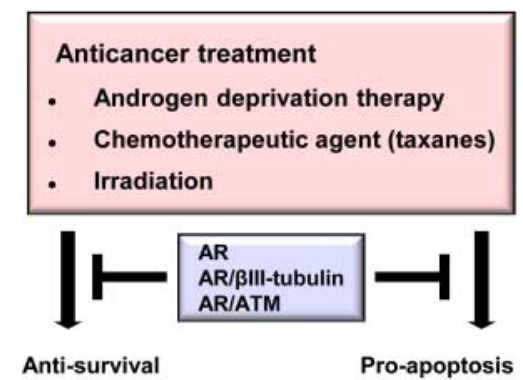

Figure 2 Schematic representation of the pro-survival and antiapoptotic properties of AR signaling that promote therapeutic resistance to androgen deprivation therapy, chemotherapeutic agents (taxanes), and radiation. Full colour version of this figure available via $\mathrm{http}: / / d x . d o i . o r g / 10.1530 / E R C-12-0232$. 
radiation ( $\mathrm{Wu}$ et al. 2007). Taken together, these findings suggest that AR signaling in prostate cancer cells suppresses the anti-survival and pro-apoptotic effects of various commonly utilized therapeutic cytotoxic and tumor-suppressive interventions, including taxanes or radiation in combination with castration (Fig. 2).

\section{Conclusions and future directions}

Oxidative stress can activate AR signaling via the following pathways: i) AR overexpression; and ii) AR activation by AR co-regulators or intracellular signal transduction pathways, thus contributing to the tumorigenesis and progression of prostate cancer, as well as the acquisition of castration resistance. In addition, AR signaling promotes the anti-apoptotic effects and survival of prostate cancer cells in the face of oxidative and cytotoxic stressors, including taxanes and radiation, through the transcriptional modulation of $\beta$ III-tubulin and ATM. Taken together, AR signaling appears to render prostate cancer cells refractory to various therapeutic interventions such as castration, radiation, and taxanes, indicating that $\mathrm{AR}$ is a comprehensive resistance factor and crucial target for prostate cancer treatment. Furthermore, administration of therapeutic interventions such as taxanes and radiation concurrent or before androgen deprivation therapy may exert improved outcome in recurrent or advanced prostate cancer. So far, numerous studies have revealed the usefulness of antioxidants including natural compounds such as vitamin D, vitamin E, carotenoids, lycopene, green tea catechins, and isoflavone, in addition to synthetic antioxidants such as NAC and DPI as a suppressor of AR signaling and prostate cancer growth (Gupta-Elera et al. 2012, Huang et al. 2012, Shiota et al. 2012). Thus, the suppression of AR signaling by antioxidants may be a promising strategy to overcome treatment resistance of prostate cancer, which will be clarified in future.

\section{Declaration of interest}

The authors declare that there is no conflict of interest that could be perceived as prejudicing the impartiality of the review.

\section{Funding}

This work was supported in part by Kakenhi Grants (22591769 and 24890160) from the Ministry of Education, Culture, Sports, Science and Technology of Japan (MEXT), and a Medical Research Promotion Grant from the Takeda Science Foundation, Japan.

\section{Acknowledgements}

We apologize to authors whose works were inadvertently overlooked or could not be cited because of space constraints. We would like to thank Edanz Group Japan for editorial assistance.

\section{References}

Acharya A, Das I, Chandhok D \& Saha T 2010 Redox regulation in cancer: a double-edged sword with therapeutic potential. Oxidative Medicine and Cellular Longevity 3 23-34. (doi:10.4161/oxim. 3.1.10095)

Andersen JK 2004 Oxidative stress in neurodegeneration: cause or consequence? Nature Medicine 10 S18-S25. (doi:10.1038/nrn1434)

Arriazu R, Pozuelo JM, Martín R, Rodríguez R \& Santamaría L 2005 Quantitative and immunohistochemical evaluation of PCNA, androgen receptors, apoptosis, and glutathione$S$-transferase P1 on preneoplastic changes induced by cadmium and zinc chloride in the rat ventral prostate. Prostate 63 347-357. (doi:10.1002/pros.20192)

Basu S \& Tindall DJ 2010 Androgen action in prostate cancer. Hormones \& Cancer 1 223-228. (doi:10.1007/ s12672-010-0044-4)

Best CJ, Gillespie JW, Yi Y, Chandramouli GV, Perlmutter MA, Gathright Y, Erickson HS, Georgevich L, Tangrea MA, Duray PH et al. 2005 Molecular alterations in primary prostate cancer after androgen ablation therapy. Clinical Cancer Research 11 6823-6834. (doi:10.1158/1078-0432. CCR-05-0585)

de Bono JS, Logothetis CJ, Molina A, Fizazi K, North S, Chu L, Chi KN, Jones RJ, Goodman OB Jr, Saad F et al. 2011 Abiraterone and increased survival in metastatic prostate cancer. New England Journal of Medicine 364 1995-2005. (doi:10.1056/NEJMoa1014618)

Bostwick DG, Alexander EE, Singh R, Shan A, Qian J, Santella RM, Oberley LW, Yan T, Zhong W, Jiang X et al. 2000 Antioxidant enzyme expression and reactive oxygen species damage in prostatic intraepithelial neoplasia and cancer. Cancer 89 123-134. (doi:10.1002/ 1097-0142(20000701)89:1<123::AID-CNCR17>3.0. $\mathrm{CO} ; 2-9)$

Brooke GN \& Bevan CL 2009 The role of androgen receptor mutations in prostate cancer progression. Current Genomics 10 18-25. (doi:10.2174/138920 209787581307)

Brooke GN, Parker MG \& Bevan CL 2008 Mechanisms of androgen receptor activation in advanced prostate cancer: differential co-activator recruitment and gene expression. Oncogene 27 2941-2950. (doi:10.1038/sj.onc.1210955)

Butler R, Leigh PN \& Gallo JM 2001 Androgen-induced up-regulation of tubulin isoforms in neuroblastoma cells. Journal of Neurochemistry 78 854-861. (doi:10.1046/j. 1471-4159.2001.00475.x) 
Chen CD, Welsbie DS, Tran C, Baek SH, Chen R, Vessella R, Rosenfeld MG \& Sawyers CL 2004 Molecular determinants of resistance to antiandrogen therapy. Nature Medicine 10 33-39. (doi:10.1038/nm972)

Choi JA, Lee JW, Kim H, Kim EY, Seo JM, Ko J \& Kim JH 2010 Pro-survival of estrogen receptor-negative breast cancer cells is regulated by a BLT2-reactive oxygen species-linked signaling pathway. Carcinogenesis 31 543-551. (doi:10.1093/carcin/bgp203)

D’Amico AV, Manola J, Loffredo M, Renshaw AA, DellaCroce A \& Kantoff PW 2004 6-Month androgen suppression plus radiation therapy vs radiation therapy alone for patients with clinically localized prostate cancer: a randomized controlled trial. Journal of the American Medical Association 18 821-827. (doi:10.1001/ jama.292.7.821)

D'Amico AV, Chen MH, Renshaw AA, Loffredo M \& Kantoff PW 2008 Androgen suppression and radiation vs radiation alone for prostate cancer: a randomized trial. Journal of the American Medical Association 23 289-295. (doi:10.1001/jama.299.3.289)

Dehm SM, Schmidt LJ, Heemers HV, Vessella RL \& Tindall DJ 2008 Splicing of a novel androgen receptor exon generates a constitutively active androgen receptor that mediates prostate cancer therapy resistance. Cancer Research 68 5469-5477. (doi:10.1158/0008-5472.CAN08-0594)

Denham JW, Steigler A, Lamb DS, Joseph D, Mameghan H, Turner S, Matthews J, Franklin I, Atkinson C, North J et al. 2005 Short-term androgen deprivation and radiotherapy for locally advanced prostate cancer: results from the Trans-Tasman Radiation Oncology Group 96.01 randomised controlled trial. Lancet Oncology 6 841-850. (doi:10.1016/S1470-2045(05)70348-X)

Denham JW, Steigler A, Lamb DS, Joseph D, Mameghan H, Turner S, Matthews J, Atkinson C, North J, Christie D et al. 2011 Short-term androgen deprivation and radiotherapy for locally advanced prostate cancer: 10-year data from the TROG 96.01 randomised trial. Lancet Oncology 12 451-459. (doi:10.1016/S1470-2045(11)70063-8)

Eigl BJ, Eggener SE, Baybik J, Ettinger S, Chi KN, Nelson C, Wang Z \& Gleave ME 2005 Timing is everything: preclinical evidence supporting simultaneous rather than sequential chemohormonal therapy for prostate cancer.

Clinical Cancer Research 11 4905-4911. (doi:10.1158/ 1078-0432.CCR-04-2140)

Ettinger SL, Sobel R, Whitmore TG, Akbari M, Bradley DR, Gleave ME \& Nelson CC 2004 Dysregulation of sterol response element-binding proteins and downstream effectors in prostate cancer during progression to androgen independence. Cancer Research 64 2212-2221. (doi:10.1158/0008-5472.CAN-2148-2)

Evdokimova V, Tognon C, Ng T, Ruzanov P, Melnyk N, Fink D, Sorokin A, Ovchinnikov LP, Davicioni E, Triche TJ et al. 2009 Translational activation of snail1 and other developmentally regulated transcription factors by YB-1 promotes an epithelial-mesenchymal transition. Cancer Cell 15 402-415. (doi:10.1016/j.ccr. 2009.03.017)

Faber PW, van Rooij HC, Schipper HJ, Brinkmann AO \& Trapman J 1993 Two different, overlapping pathways of transcription initiation are active on the TATA-less human androgen receptor promoter. The role of Sp1. Journal of Biological Chemistry 268 9296-9301.

Fajardo AM, MacKenzie DA, Ji M, Deck LM, Vander Jagt DL, Thompson TA \& Bisoffi M 2012 The curcumin analog ca27 down-regulates androgen receptor through an oxidative stress mediated mechanism in human prostate cancer cells. Prostate 72 612-625. (doi:10.1002/pros.21464)

Fizazi K, Lesaunier F, Delva R, Gravis G, Rolland F, Priou F, Ferrero JM, Houedé N, Mourey L, Theodore C et al. 2012 A phase III trial of docetaxel-estramustine in high-risk localised prostate cancer: a planned analysis of response, toxicity and quality of life in the GETUG 12 trial.

European Journal of Cancer 48 209-217. (doi:10.1016/ j.ejca.2011.10.015)

Grad JM, Dai JL, Wu S \& Burnstein KL 1999 Multiple androgen response elements and a Myc consensus site in the androgen receptor (AR) coding region are involved in androgen-mediated up-regulation of AR messenger RNA. Molecular Endocrinology 13 1896-1911. (doi:10.1210/ me.13.11.1896)

Granfors T, Damber JE, Bergh A, Landström M, Löfroth PO \& Widmark A 1997 Combined castration and fractionated radiotherapy in an experimental prostatic adenocarcinoma. International Journal of Radiation Oncology, Biology, Physics 39 1031-1036. (doi:10.1016/S03603016(97)00559-2)

Gregory CW, Hamil KG, Kim D, Hall SH, Pretlow TG, Mohler JL \& French FS 1998 Androgen receptor expression in androgen-independent prostate cancer is associated with increased expression of androgenregulated genes. Cancer Research 58 5718-5724.

Guo Z, Yang X, Sun F, Jiang R, Linn DE, Chen H, Chen H, Kong X, Melamed J, Tepper CG et al. 2009 A novel androgen receptor splice variant is up-regulated during prostate cancer progression and promotes androgen depletion-resistant growth. Cancer Research 69 2305-2313. (doi:10.1158/0008-5472. CAN-08-3795)

Gupta-Elera G, Garrett AR, Robison RA \& O'Neill KL 2012 The role of oxidative stress in prostate cancer. European Journal of Cancer Prevention 21 155-162. (doi:10.1097/ CEJ.0b013e32834a8002)

Haigis MC \& Yankner BA 2010 The aging stress response. Molecular Cell 40 333-344. (doi:10.1016/j.molcel. 2010.10.002)

Heemers HV \& Tindall DJ 2007 Androgen receptor (AR) coregulators: a diversity of functions converging on and regulating the AR transcriptional complex. Endocrine Reviews 28 778-808. (doi:10.1210/er.2007-0019) 
Hennig R, Osman T, Esposito I, Giese N, Rao SM, Ding XZ, Tong WG, Büchler MW, Yokomizo T, Friess $\mathrm{H}$ et al. 2008 BLT2 is expressed in PanINs, IPMNs, pancreatic cancer and stimulates tumour cell proliferation. British Journal of Cancer 99 1064-1073. (doi:10.1038/sj.bjc. 6604655)

Hu R, Dunn TA, Wei S, Isharwal S, Veltri RW, Humphreys E, Han M, Partin AW, Vessella RL, Isaacs WB et al. 2009 Ligand-independent androgen receptor variants derived from splicing of cryptic exons signify hormone-refractory prostate cancer. Cancer Research 69 16-22. (doi:10.1158/ 0008-5472.CAN-08-2764)

Huang WC, Zhau HE \& Chung LW 2010 Androgen receptor survival signaling is blocked by anti- $\beta 2$-microglobulin monoclonal antibody via a MAPK/lipogenic pathway in human prostate cancer cells. Journal of Biological Chemistry 285 7947-7956. (doi:10.1074/jbc.M109. 092759)

Huang WC, Li X, Liu J, Lin J \& Chung LW 2012 Activation of androgen receptor, lipogenesis, and oxidative stress converged by SREBP-1 is responsible for regulating growth and progression of prostate cancer cells. Molecular Cancer Research 10 133-142. (doi:10.1158/ 1541-7786.MCR-11-0206)

Ihsan A, Wang X, Liu Z, Wang Y, Huang X, Liu Y, Yu H, Zhang H, Li T, Yang C et al. 2011 Long-term mequindox treatment induced endocrine and reproductive toxicity via oxidative stress in male Wistar rats. Toxicology and Applied Pharmacology 252 281-288. (doi:10.1016/j.taap. 2011.02.020)

Ikeda Y, Aihara K, Akaike M, Sato T, Ishikawa K, Ise T, Yagi S, Iwase T, Ueda Y, Yoshida S et al. 2010 Androgen receptor counteracts doxorubicin-induced cardiotoxicity in male mice. Molecular Endocrinology 24 1338-1348. (doi:10.1210/me.2009-0402)

Jones CU, Hunt D, McGowan DG, Amin MB, Chetner MP, Bruner DW, Leibenhaut MH, Husain SM, Rotman M, Souhami L et al. 2011 Radiotherapy and short-term androgen deprivation for localized prostate cancer. New England Journal of Medicine 365 107-118. (doi:10.1056/ NEJMoa1012348)

Kaminski JM, Hanlon AL, Joon DL, Meistrich M, Hachem P \& Pollack A 2003 Effect of sequencing of androgen deprivation and radiotherapy on prostate cancer growth. International Journal of Radiation Oncology, Biology, Physics 57 24-28. (doi:10.1016/S0360-3016(03) 00539-X)

Kattan MW, Zelefsky MJ, Kupelian PA, Cho D, Scardino PT, Fuks Z \& Leibel SA 2003 Pretreatment nomogram that predicts 5-year probability of metastasis following threedimensional conformal radiation therapy for localized prostate cancer. Journal of Clinical Oncology 21 4568-4571. (doi:10.1200/JCO.2003.05.046)

Khandrika L, Kumar B, Koul S, Maroni P \& Koul HK 2009 Oxidative stress in prostate cancer. Cancer Letters 282 125-136. (doi:10.1016/j.canlet.2008.12.011)
Koka PS, Mondal D, Schultz M, Abdel-Mageed AB \& Agrawal KC 2010 Studies on molecular mechanisms of growth inhibitory effects of thymoquinone against prostate cancer cells: role of reactive oxygen species. Experimental Biology and Medicine 235 751-760. (doi:10.1258/ebm.2010.009369)

Kosaka T, Miyajima A, Shirotake S, Suzuki E, Kikuchi E \& Oya M 2011 Long-term androgen ablation and docetaxel up-regulate phosphorylated Akt in castration resistant prostate cancer. Journal of Urology 85 2376-2381. (doi:10.1016/j.juro.2011.02.016)

Kumar JK, Ping RY, Teong HF, Goh S \& Clément MV 2011 Activation of a non-genomic Pim-1/Bad-Pser75 module is required for an efficient pro-survival effect of $\mathrm{Bcl}-\mathrm{xL}$ induced by androgen in LNCaP cells. International Journal of Biochemistry \& Cell Biology 43 594-603. (doi:10.1016/j.biocel.2010.12.017)

Kuruma H, Egawa S, Oh-Ishi M, Kodera Y, Satoh M, Chen W, Okusa H, Matsumoto K, Maeda T \& Baba S 2005 High molecular mass proteome of androgen-independent prostate cancer. Proteomics 5 1097-1112. (doi:10.1002/pmic. 200401115)

Lee SO, Lou W, Hou M, de Miguel F, Gerber L \& Gao AC 2003 Interleukin-6 promotes androgen-independent growth in LNCaP human prostate cancer cells. Clinical Cancer Research 9 370-376.

Lee JG, Zheng R, McCafferty-Cepero JM, Burnstein KL, Nanus DM \& Shen R 2009 Endothelin-1 enhances the expression of the androgen receptor via activation of the c-myc pathway in prostate cancer cells. Molecular Carcinogenesis 48 141-149. (doi:10.1002/mc. 20462)

Lee JW, Kim GY \& Kim JH 2012 Androgen receptor is up-regulated by a BLT2-linked pathway to contribute to prostate cancer progression. Biochemical and Biophysical Research Communications 420 428-433. (doi:10.1016/ j.bbrc.2012.03.012)

Locke JA, Guns ES, Lubik AA, Adomat HH, Hendy SC, Wood CA, Ettinger SL, Gleave ME \& Nelson CC 2008 Androgen levels increase by intratumoral de novo steroidogenesis during progression of castration-resistant prostate cancer. Cancer Research 68 6407-6415. (doi:10.1158/0008-5472.CAN-07-5997)

Mahajan K, Coppola D, Rawal B, Chen YA, Lawrence HR, Engelman RW, Lawrence NJ \& Mahajan NP 2012 Ack1-mediated androgen receptor phosphorylation modulates radiation resistance in castration-resistant prostate cancer. Journal of Biological Chemistry 287 22112-22122. (doi:10.1074/ jbc.M112.357384)

Mariani M, Zannoni GF, Sioletic S, Sieber S, Martino C, Martinelli E, Coco C, Scambia G, Shahabi S \& Ferlini C 2012 Gender influences the class III and V $\beta$-tubulin ability to predict poor outcome in colorectal cancer. Clinical Cancer Research 18 2964-2975. (doi:10.1158/ 1078-0432.CCR-11-2318) 
Miyamoto H, Messing EM \& Chang C 2004 Androgen deprivation therapy for prostate cancer: current status and future prospects. Prostate 61 332-353. (doi:10.1002/ pros.20115)

Mizokami A, Yeh SY \& Chang C 1994 Identification of $3^{\prime}, 5^{\prime}$-cyclic adenosine monophosphate response element and other cis-acting elements in the human androgen receptor gene promoter. Molecular Endocrinology 8 77-88. (doi:10.1210/me.8.1.77)

Montgomery RB, Mostaghel EA, Vessella R, Hess DL, Kalhorn TF, Higano CS, True LD \& Nelson PS 2008 Maintenance of intratumoral androgens in metastatic prostate cancer: a mechanism for castration-resistant tumor growth. Cancer Research 68 4447-4454. (doi:10.1158/0008-5472.CAN-08-0249)

Niraula S, Chi K \& Joshua AM 2012 Beyond castrationdefining future directions in the hormonal treatment of prostate cancer. Hormones \& Cancer 3 3-13. (doi:10.1007/s12672-011-0096-0)

Nishiyama T 2012 Androgen deprivation therapy in combination with radiotherapy for high-risk clinically localized prostate cancer. Journal of Steroid Biochemistry and Molecular Biology 129 179-190. (doi:10.1016/j. jsbmb.2011.12.019)

Ohkuma M, Funato N, Higashihori N, Murakami M, Ohyama K \& Nakamura M 2007 Unique CCT repeats mediate transcription of the TWIST1 gene in mesenchymal cell lines. Biochemical and Biophysical Research Communications 352 925-931. (doi:10.1016/j.bbrc.2006.11.114)

Pang ST, Dillner K, Wu X, Pousette A, Norstedt G \& FloresMorales A 2002 Gene expression profiling of androgen deficiency predicts a pathway of prostate apoptosis that involves genes related to oxidative stress. Endocrinology 143 4897-4906. (doi:10.1210/en.2002-220327)

Paravicini TM \& Touyz RM 2006 Redox signaling in hypertension. Cardiovascular Research 71 247-258. (doi:10.1016/j.cardiores.2006.05.001)

Pathak S, Singh R, Verschoyle RD, Greaves P, Farmer PB, Steward WP, Mellon JK, Gescher AJ \& Sharma RA 2008 Androgen manipulation alters oxidative DNA adduct levels in androgen-sensitive prostate cancer cells grown in vitro and in vivo. Cancer Letters 261 74-83. (doi:10.1016/j.canlet.2007.11.015)

Pham CG, Bubici C, Zazzeroni F, Knabb JR, Papa S, Kuntzen C \& Franzoso G 2007 Upregulation of Twist-1 by NF- $\kappa \mathrm{B}$ blocks cytotoxicity induced by chemotherapeutic drugs. Molecular and Cellular Biology 27 3920-3935. (doi:10.1128/MCB.01219-06)

Pinthus JH, Bryskin I, Trachtenberg J, Lu JP, Singh G, Fridman E \& Wilson BC 2007 Androgen induces adaptation to oxidative stress in prostate cancer: implications for treatment with radiation therapy. Neoplasia 9 68-80. (doi:10.1593/neo.06739)

Quirós I, Sáinz RM, Hevia D, García-Suárez O, Astudillo A, Rivas M \& Mayo JC 2009 Upregulation of manganese superoxide dismutase (SOD2) is a common pathway for neuroendocrine differentiation in prostate cancer cells. International Journal of Cancer 125 1497-1504. (doi:10.1002/ijc.24501)

Ray PD, Huang BW \& Tsuji Y 2012 Reactive oxygen species (ROS) homeostasis and redox regulation in cellular signaling. Cellular Signaling 24 981-990. (doi:10.1016/ j.cellsig.2012.01.008)

Ripple MO, Henry WF, Rago RP \& Wilding G 1997 Prooxidant-antioxidant shift induced by androgen treatment of human prostate carcinoma cells. Journal of the National Cancer Institute 89 40-48. (doi:10.1093/jnci/ 89.1.40)

Roos G \& Messens J 2011 Protein sulfenic acid formation: from cellular damage to redox regulation. Free Radical Biology \& Medicine 51 314-326. (doi:10.1016/ j.freeradbiomed.2011.04.031)

Scher HI \& Sawyers CL 2005 Biology of progressive, castration-resistant prostate cancer: directed therapies targeting the androgen-receptor signaling axis. Journal of Clinical Oncology 23 8253-8261. (doi:10.1200/JCO. 2005.03.4777)

Scher HI, Fizazi K, Saad F, Taplin ME, Sternberg CN, Miller MD, de Wit R, Mulders P, Chi KN, Shore ND et al. 2012 Increased survival with enzalutamide in prostate cancer after chemotherapy. New England Journal of Medicine 367 1187-1197. (doi:10.1056/ NEJMoa1207506)

Shan W, Zhong W, Zhao R \& Oberley TD 2010 Thioredoxin 1 as a subcellular biomarker of redox imbalance in human prostate cancer progression. Free Radical Biology \& Medicine 49 2078-2087. (doi:10.1016/j.freeradbiomed. 2010.10.691)

Shariat SF, Andrews B, Kattan MW, Kim J, Wheeler TM \& Slawin KM 2001 Plasma levels of interleukin-6 and its soluble receptor are associated with prostate cancer progression and metastasis. Urology 58 1008-1015. (doi:10.1016/S0090-4295(01)01405-4)

Sharifi N, Hurt EM, Thomas SB \& Farrar WL 2008 Effects of manganese superoxide dismutase silencing on androgen receptor function and gene regulation: implications for castration-resistant prostate cancer. Clinical Cancer Research 14 6073-6080. (doi:10.1158/1078-0432.CCR08-0591)

Shigemura K, Sung SY, Kubo H, Arnold RS, Fujisawa M, Gotoh A, Zhau HE \& Chung LW 2007 Reactive oxygen species mediate androgen receptor- and serum starvationelicited downstream signaling of ADAM9 expression in human prostate cancer cells. Prostate 67 722-731. (doi:10.1002/pros.20565)

Shiota M, Izumi H, Onitsuka T, Miyamoto N, Kashiwagi E, Kidani A, Yokomizo A, Naito S \& Kohno K 2008 a Twist promotes tumor cell growth through YB-1 expression. Cancer Research 68 98-105. (doi:10.1158/0008-5472. CAN-07-2981)

Shiota M, Izumi H, Onitsuka T, Miyamoto N, Kashiwagi E, Kidani A, Hirano G, Takahashi M, Naito S \& Kohno K 
$2008 b$ Twist and p53 reciprocally regulate target genes via direct interaction. Oncogene 27 5543-5553. (doi:10.1038/onc.2008.176)

Shiota M, Izumi H, Tanimoto A, Takahashi M, Miyamoto N, Kashiwagi E, Kidani A, Hirano G, Masubuchi D, Fukunaka Y et al. 2009 Programmed cell death protein 4 down-regulates Y-box binding protein-1 expression via a direct interaction with Twist1 to suppress cancer cell growth. Cancer Research 69 3148-3156. (doi:10.1158/ 0008-5472.CAN-08-2334)

Shiota M, Yokomizo A, Tada Y, Inokuchi J, Kashiwagi E, Masubuchi D, Eto M, Uchiumi T \& Naito S 2010 Castration resistance of prostate cancer cells caused by castration-induced oxidative stress through Twist 1 and androgen receptor overexpression. Oncogene 29 237-250. (doi:10.1038/onc.2009.322)

Shiota M, Yokomizo A \& Naito S 2011 $a$ Oxidative stress and androgen receptor signaling in the development and progression of castration-resistant prostate cancer. Free Radical Biology \& Medicine 51 1320-1328. (doi:10. 1016/j.freeradbiomed.2011.07.011)

Shiota M, Yokomizo A \& Naito S $2011 b$ Increased androgen receptor transcription: a cause of castration-resistant prostate cancer and a possible therapeutic target. Journal of Molecular Endocrinology 47 R25-R41. (doi:10.1530/JME-11-0018)

Shiota M, Takeuchi A, Song Y, Yokomizo A, Kashiwagi E, Uchiumi T, Kuroiwa K, Tatsugami K, Fujimoto N, Oda Y et al. 2011c Y-box binding protein-1 promotes androgenindependent prostate cancer cell growth through androgen receptor expression. Endocrine-Related Cancer 18 505-517. (doi:10.1530/ERC-11-0017)

Shiota M, Yokomizo A \& Naito S 2011d Androgen receptor cofactors in prostate cancer: potential therapeutic targets of castration-resistant prostate cancer. Current Cancer Drug Targets 11 870-881. (doi:10.2174/ 156800911796798904)

Shiota M, Yokomizo A, Kashiwagi E, Takeuchi A, Fujimoto N, Uchiumi T \& Naito S 2011e Peroxiredoxin 2 in nucleus and cytoplasm distinctly regulates androgen receptor signaling in prostate cancer cells. Free Radical Biology \& Medicine 51 78-87. (doi:10.1016/j.freeradbiomed. 2011.04.001)

Shiota M, Takeuchi A, Yokomizo A, Kashiwagi E, Tatsugami K, Kuroiwa K \& Naito S 2012 Androgen receptor signaling regulates cell growth and vulnerability to doxorubicin in bladder cancer. Journal of Urology 188 276-286. (doi:10.1016/j.juro.2012.02.2554)

Soliman D, Hamming KS, Matemisz LC \& Light PE 2009 Reactive oxygen species directly modify sodium-calcium exchanger activity in a splice variant-dependent manner. Journal of Molecular \& Cellular Cardiology 47 595-602. (doi:10.1016/j.yjmcc.2009.05.011)

Stanbrough M, Bubley GJ, Ross K, Golub TR, Rubin MA, Penning TM, Febbo PG \& Balk SP 2006 Increased expression of genes converting adrenal androgens to testosterone in androgen-independent prostate cancer. Cancer Research 66 2815-2825. (doi:10.1158/00085472.CAN-05-4000)

Sun S, Sprenger CC, Vessella RL, Haugk K, Soriano K, Mostaghel EA, Page ST, Coleman IM, Nguyen HM, Sun $\mathrm{H}$ et al. 2010 Castration resistance in human prostate cancer is conferred by a frequently occurring androgen receptor splice variant. Journal of Clinical Investigation 120 2715-2730. (doi:10.1172/JCI41824)

Takeo K, Kawai T, Nishida K, Masuda K, Teshima-Kondo S, Tanahashi T \& Rokutan K 2009 Oxidative stress-induced alternative splicing of transformer $2 \beta$ (SFRS10) and CD44 pre-mRNAs in gastric epithelial cells. American Journal of Physiology. Cell Physiology 297 C330-C338. (doi:10.1152/ajpcell.00009.2009)

Tam NN, Gao Y, Leung YK \& Ho SM 2003 Androgenic regulation of oxidative stress in the rat prostate: involvement of $\mathrm{NAD}(\mathrm{P}) \mathrm{H}$ oxidases and antioxidant defense machinery during prostatic involution and regrowth. American Journal of Pathology 163 2513-2522. (doi:10.1016/S0002-9440(10)63606-1)

Thomas R \& Sharifi N 2012 SOD mimetics: a novel class of androgen receptor inhibitors that suppresses castrationresistant growth of prostate cancer. Molecular Cancer Therapeutics 11 87-97. (doi:10.1158/1535-7163. MCT-11-0540)

Titus MA, Schell MJ, Lih FB, Tomer KB \& Mohler JL 2005 Testosterone and dihydrotestosterone tissue levels in recurrent prostate cancer. Clinical Cancer Research 11 4653-4657. (doi:10.1158/1078-0432.CCR-05-0525)

Trachootham D, Alexandre J \& Huang P 2009 Targeting cancer cells by ROS-mediated mechanisms: a radical therapeutic approach? Nature Reviews Drug Discovery 8 579-591. (doi:10.1038/nrd2803)

Uramoto H, Izumi H, Ise T, Tada M, Uchiumi T, Kuwano M, Yasumoto K, Funa K \& Kohno K 2002 p73 Interacts with c-Myc to regulate Y-box-binding protein-1 expression. Journal of Biological Chemistry 277 31694-31702. (doi:10.1074/jbc.M200266200)

Wallner L, Dai J, Escara-Wilke J, Zhang J, Yao Z, Lu Y, Trikha M, Nemeth JA, Zaki MH \& Keller ET 2006 Inhibition of interleukin-6 with CNTO328, an antiinterleukin-6 monoclonal antibody, inhibits conversion of androgen-dependent prostate cancer to an androgenindependent phenotype in orchiectomized mice. Cancer Research 66 3087-3095. (doi:10.1158/0008-5472. CAN-05-3447)

Watson PA, Chen YF, Balbas MD, Wongvipat J, Socci ND, Viale A, Kim K \& Sawyers CL 2010 Constitutively active androgen receptor splice variants expressed in castrationresistant prostate cancer require full-length androgen receptor. PNAS 107 16759-16765. (doi:10.1073/pnas.1012443107)

Wu CT, Chen WC, Liao SK, Hsu CL, Lee KD \& Chen MF 2007 The radiation response of hormone-resistant prostate cancer induced by long-term hormone therapy. Endocrine-Related Cancer 14 633-643. (doi:10.1677/ ERC-07-0073) 
$\mathrm{Xu} \mathrm{H} \&$ Chu S 2007 ENaC $\boldsymbol{\alpha}$-subunit variants are expressed in lung epithelial cells and are suppressed by oxidative stress. American Journal of Physiology. Lung Cellular and Molecular Physiology 293 L1454-L1462. (doi:10.1152/ajplung.00248.2007)

Yang L, Xie S, Jamaluddin MS, Altuwaijri S, Ni J, Kim E, Chen YT, Hu YC, Wang L, Chuang KH et al. 2005 Induction of androgen receptor expression by phosphatidylinositol 3-kinase/Akt downstream substrate, FOXO3a, and their roles in apoptosis of $\mathrm{LNCaP}$ prostate cancer cells. Journal of Biological Chemistry $\mathbf{2 8 0}$ 33558-33565. (doi:10.1074/jbc.M504461200)

Yokomizo A, Shiota M, Kashiwagi E, Kuroiwa K, Tatsugami K, Inokuchi J, Takeuchi A \& Naito S 2011 Statins reduce the androgen sensitivity and cell proliferation by decreasing the androgen receptor protein in prostate cancer cells. Prostate 71 298-304. (doi:10.1002/pros.21243)

Yoo MH, Song H, Woo CH, Kim H \& Kim JH 2004 Role of the BLT2, a leukotriene B4 receptor, in Ras transformation. Oncogene 23 9259-9268. (doi:10.1038/sj. onc.1208151)

Yuan H, Gong A \& Young CY 2005 Involvement of transcription factor $\mathrm{Sp} 1$ in quercetin-mediated inhibitory effect on the androgen receptor in human prostate cancer cells. Carcinogenesis 26 793-801. (doi:10.1093/carcin/bgi021)

Zegarra-Moro OL, Schmidt LJ, Huang H \& Tindall DJ 2002 Disruption of androgen receptor function inhibits proliferation of androgen-refractory prostate cancer cells. Cancer Research 62 1008-1013.
Zhang L, Altuwaijri S, Deng F, Chen L, Lal P, Bhanot UK, Korets R, Wenske S, Lilja HG, Chang C et al. 2009 $\mathrm{NF}-\kappa \mathrm{B}$ regulates androgen receptor expression and prostate cancer growth. American Journal of Pathology 175 489-499. (doi:10.2353/ajpath.2009. 080727)

Zhao Y, Ao H, Chen L, Sottas CM, Ge RS, Li L \& Zhang Y 2012 Mono-(2-ethylhexyl) phthalate affects the steroidogenesis in rat Leydig cells through provoking ROS perturbation. Toxicology in Vitro 26 950-955. (doi:10.1016/j.tiv.2012.04.003)

Zhu ML, Partin JV, Bruckheimer EM, Strup SE \& Kyprianou N 2008 TGF- $\beta$ signaling and androgen receptor status determine apoptotic cross-talk in human prostate cancer cells. Prostate 68 287-295. (doi:10.1002/pros.20698)

Zietman AL, Prince EA, Nakfoor BM \& Park JJ 1997 Androgen deprivation and radiation therapy: sequencing studies using the Shionogi in vivo tumor system. International Journal of Radiation Oncology, Biology, Physics 38 1067-1070. (doi:10.1016/S03603016(97)00309-X)

Received in final form 18 September 2012 Accepted 1 October 2012 Made available online as an Accepted Preprint 2 October 2012 